general secretary, for assisted suicide prompted the organisation to change its name from EXIT, in order to distance itself from his activities. ${ }^{5}$ Then as now the organisation clearly stated that it does not condone operating outside the law, although it does seek a change in the law.

Surely a case is to be made for reform, but not along the permissive lines that have been proposed, including those in a controversial editorial in this journal. ${ }^{6}$ Rather, what is needed is greater clarity in the definition and application of the offence. The prosecutions to date in England and Wales show a body of law that is replete with uncertainty, obfuscation, and injustice.

Consider the "classic" case of "leaving the pills." Certainly convictions have been made in such circumstances, but this does not explain why one case was dismissed by the court since the accused "only provided the option," which was, said the judge, "not enough."” Furthermore no health professional has been prosecuted for the offence in this jurisdiction despite at least anecdotal evidence indicating that such assistance does occur. ${ }^{8}$

No less confusing is the (il)legality of "death tourism." After Reginald Crew was assisted to die in Switzerland, uncertainty prevailed over whether his wife, Win, had committed an offence in helping him to travel there. Although the police declined to prosecute in that case, they have yet to promulgate their prosecuting policy on this issue.

Perhaps most objectionable, however, is a ruling reported in 1989. Mr and Mrs Johnson were convicted of assisting the suicide of their daughter Sara (who also had motor neurone disease) after she had taken an overdose. They did nothing positively to assist Sara: as the judge said they were guilty of "purely negative conduct" in sitting with her and honouring her request not to summon medical intervention. ${ }^{9}$

That conviction is problematic for at least three reasons. Firstly, it implies that one must not inform one's close friends or relations as to any suicidal intent for fear of exposing them to criminality. That hardly sits well with the intentions behind the suicide bill, where it was stated that suicidal people should be dealt with compassionately (hence its decriminalisation). ${ }^{10}$ Secondly, supporters of the bill believed that the offence would require some "clear, positive element," so the Johnsons' convictions again seem to frustrate parliamentary intention.

But finally, and perhaps most importantly, in the healthcare context the conviction conflicts with the assumed validity of a patient's refusal of treatment, whether made contemporaneously or in advance of incompetence. Provided of course that Sara was competent (and perhaps that was the sticking point), she seemingly should have enjoyed the same rights as were successfully asserted by ventilator dependent Ms B. ${ }^{11}$ Yet, while Ms B's trust was found liable in damages for violating the principle of respect for a patient's autonomy and thereby trespassing against $\mathrm{B}$, the Johnsons were found guilty for honouring that principle. What is the basis for the distinction? Is it simply because the Johnsons were not health professionals in a healthcare setting? Are advance directives valid only in such a context?

A case exists, at first sight, for a fresh look at this area. The current law rightly adopts a compromise between the more extreme "right to die" and right to life positions, as seen in those lenient sentences passed down on those (usually "mercy killers") convicted of the offence. Nevertheless, greater clarity is needed both here and in other aspects of the law governing the end(ing) of life. ${ }^{12}$ The best approach might be to heed recent calls for an investigation by a new House of Lords Select Committee or Royal Commission. Quite what shape the law will ultimately take remains to be seen; what should be clear, however, is that a review is desperately needed.

Richard Huxtable lecturer in medical law and ethics

Centre for Ethics in Medicine, University of Bristol, Bristol BS2 8BH (R.Huxtable@bristol.ac.uk)

\section{Competing interests: None declared.}

1 Wainwright M. Arrested euthanasia society chief resigns. Guardian 2003 15 December: 11

Lord Joffe. Patient (assisted dying) bill (HL). wwwpublications. parliament.uk/pa/ld200203/ldbills/037/2003037.pdf (accessed 28 Jan 2003).

$3 \mathrm{R}$ (on the application of Pretty) $v$ DPP [2002] 1 FLR 268 (House of Lords).

4 Application No 2346/02 Pretty $v$ UK (2002) 35 EHRR 1 (European Court of Human Rights)

5 EXIT campaigner gaoled. Guardian 198131 October:1, 4.

Doyal L, Doyal L. Why active euthanasia and physician assisted suicide should be legalised. BMJ 2001;323:1079-80.

7 Gorman F Teenager cleared of aiding suicide. Times 199323 September:3.

Nonton C. Family doctors a it helping thousts of patents to die. Sunday Times 199815 November:2. Probation for parents who watched their daughter die. Independent 198 18 November: 3 .

10 House of Commons. Parliamentary debate (Hansard). 196114 July;644: col 837.

1 Re B (Adult: Refusal of Medical Treatment) [2002] 2 All ER 449.

12 Huxtable R. Get out of jail free? The doctrine of double effect in English law. Palliat Med 2004; 18: 62-8.

\title{
Physical activity and coronary heart disease
}

\section{Fifty years of research confirms inverse relationship}

$\mathrm{F}$ ifty years ago the first empirical investigation of what was subsequently termed the exercise hypothesis-physical activity reduces the occurrence of coronary heart disease-was undertaken by Morris et al. ${ }^{1}$ Using data from two cohorts of British workers, they reported lower rates of coronary heart disease in bus conductors than in less occupationally active bus drivers, and in postmen relative to deskbound telephonists and other office based employees. Although this research was pioneering, it was not without its shortcomings. Early statistical methods were limited in their capacity to explore the issue of confounding-for example, it was possible that higher levels of overweight, high blood 
pressure, stress, or pre-existing ischaemia in the less active groups, rather than their sedentary behaviour, placed them at increased risk of coronary heart disease. Further, the study focused exclusively on work activity. Morris et al, and subsequently Paffenbarger et al, went on to address these issues, showing physical activity in leisure time to be cardioprotective, an effect that held after a range of covariates were controlled for. $^{23}$

The work of these researchers prompted a series of other investigations, including the study of the association between cardiorespiratory fitness-a physiological outcome of physical activity and therefore an objective proxy for it-and cardiovascular disease, which showed that higher levels, which were none the less eminently attainable by non-athletes, conferred protection against coronary heart disease. ${ }^{4}$ These studies, and those of physical activity, represent a range of methodological rigour and have, with few exceptions, shown an inverse association between activity and coronary heart disease, which is testimony to the robustness of the relation. Until recently this research has focused on men. In the past two decades, however, the same degree of consistency has been observed in women-a dose-response effect is again evident, with the highest rates of coronary heart disease seen in people who are inactive or have low cardiorespiratory fitness. This level of risk may be of slightly lower magnitude than that reported in men.

We still do not fully understand the pathways underlying the protective effect of physical exertion against coronary heart disease. In addition to well established improvements in blood pressure, lipid profile, insulin sensitivity, and body weight, activity may improve endothelial function and coronary blood flow and may be associated with beneficial changes in haemostatic and inflammatory variables. ${ }^{56}$ These warrant further examination. Given the public's reluctance to be physically active, future research also needs to identify the minimum dose (the total volume of activity, as well as the intensity, duration, and frequency), type (aerobic, strength training), and mode (walking, swimming) of activity associated with reduced coronary heart disease risk that will be most palatable to the sedentary populations. For the prevention of a range of chronic diseases, including coronary heart disease, the current recommendation is 30 minutes or more of moderately intense aerobic activity such as brisk walking or cycling on five or more occasions per week. ${ }^{7}$ Worryingly, however, the prevalence of activity in most Western societies does not match this: in England, for example, only about one quarter of men and women currently achieve this level, ${ }^{8}$ and these figures are lower still in elderly people.

For the sedentary majority, commonly cited barriers to participation include inconvenience (for example, lack of easily accessible facilities) and danger (in the United States injuries and fatalities among pedestrians and cyclists far exceed those for car occupants). Therefore, efforts to promote activity that focus on personal behaviour change-often delivered via face to face contact in a small group-may not be sufficiently effective. An alternative approach is one that also recognises the importance of physical and social environments as crucial determinants of physical activity both of a utilitarian nature and for leisure. Utili- tarian activity levels seem to be higher in residentially dense neighbourhoods in mixed use (business and residential) that offer a greater concentration of street connections than neighbourhoods that are more sprawling in design where, presumably by necessity, travel by motorised transportation predominates. ${ }^{9}$ Perhaps because of these differing degrees of physical activity, people residing in more compact neighbourhoods are also less likely to report obesity and hypertension. ${ }^{10}$ Moreover, in Japan the life expectancy of people with more easy access to facilities conducive to physical activity in leisure time, such as parks and tree lined streets, exceeds that of people without such resources, even after the obvious and important socioeconomic differences between such areas are taken into account. ${ }^{11}$

Although the governments of many countries, including the United Kingdom, have the opportunities to implement such changes in urban form in order to make environments more conducive to physical activity, what they may lack is the political resolve. This may be short sighted. Given the high prevalence of sedentary behaviour and its association with a range of chronic diseases-which include not only coronary heart disease, but also stroke, type 2 diabetes, certain cancers, and osteoporotic fractures ${ }^{12}$-modification of physical activity may, as Morris indicated four decades after the publication of his seminal work, represent today's best buy in public health. $^{13}$

\section{G David Batty senior research fellow in epidemiology}

Department of Social Medicine, Institute of Public Health, University of Copenhagen, Blegdamsvej 3, DK-2200 Copenhagen N, Denmark (david.batty@pubhealth.ku.dk)

\section{I-Min Lee associate professor of medicine}

Division of Preventive Medicine, Department of Medicine, Brigham and Women's Hospital and Harvard Medical School, 900

Commonwealth Avenue East, Boston, MA 02215, USA

Funding: GDB is supported by a fellowship from the University of Copenhagen.

Competing interests: None declared.

1 Morris JN, Heady JA, Raffle PAB, Roberts CG, Parks JW. Coronary heartdisease and physical activity of work. Lancet 1953;ii:1053-7, 1111-20.

2 Morris JN, Chave SPW, Adam C, Sirey C, Epstein L, Sheehan DJ. Vigorous exercise in leisure-time and the incidence of coronary heart-disease. Lancet 1973;i:333-9.

3 Paffenbarger RS, Wing AL, Hyde RT. Physical activity as an index of heart attack risk in college alumni. Am J Epidemiol 1978;108:161-75.

4 Wilhelmsen L, Bjure J, Ekstrom-Jodal B, Aurell M, Grimby G, Svardsudd K, Wilhelmsen L, Bjure J, Ekstrom-jodal B, Aurell M, Grimby G, Svardsudd K,
et al. Nine years' follow-up of a maximal exercise test in a random populaet al. Nine years' follow-up of a maximal exercise test in a
tion sample of middle-aged men. Cardiology 1981;68:1-8.

5 Hambrecht R, Wolf A, Gielen S, Linke A, Hofer J, Erbs S, et al. Effect of exercise on coronary endothelial function in patients with coronary artery disease. N Engl J Med 2000;342:454-60.

6 Wannamethee SG, Lowe GD, Whincup PH, Rumley A, Walker M, Lennon L. Physical activity and hemostatic and inflammatory variables in elderly men. Circulation 2002;105:1785-90.

7 Pate RR, Pratt M, Blair SN, Haskell WL, Macera CA, Bouchard C. Physical activity and public health. JAMA 1995;273:402-7.

cal activity and public health.JAMA 1995;273:402-7.

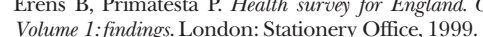

9 Saelens BE, Sallis JF, Frank LD. Environmental correlates of walking and Saelens BE, Sallis JF, Frank LD. Environmental correlates of walking and
cycling: findings from the transportation, urban design, and planning literatures. Ann Behav Med 2003;25:80-91.

10 Ewing R, Schmid T, Killingsworth R, Zlot A, Raudenbush S. Relationship between urban sprawl and physical activity, obesity, and morbidity. Am J Health Promot 2003;18:47-57.

11 Takano T, Nakamura K, Watanabe M. Urban residential environments and senior citizens' longevity in megacity areas: the importance of walkable green spaces. J Epidemiol Community Health 2002;56:913-8.

12 US Department of Health and Human Services. Physical activity and health: a report of the surgeon general. Atlanta: US Department of Health health: a report of the surgeom
and Human Services, 1996.

13 Morris JN. Exercise in the prevention of coronary heart disease: today's best buy in public health. Med Sci Sports Exercise 1994;26:807-14.
beris 